Editorial

\title{
A RBMFC e a difusão do conhecimento em APS / MFC
}

\section{Editorial The Brazilian Journal of Family Community Medicine and dissemination of knowledge on Primary Care and Family Health}

Carlos Eduardo Aguilera Campos*

Nesta oportunidade gostaríamos de destacar alguns fatos relevantes na trajetória da RBMFC. Tem sido muito positiva a receptividade da RBMFC junto aos graduandos em Medicina em todo o país. Desde a edição número 3, fizemos um esforço de catalogar e enviar exemplares para todas as bibliotecas dos cursos de Medicina. Contamos para isto com a colaboração da ABEM, que gentilmente nos cedeu a sua lista de seus filiados. Desde então houve um retorno muito positivo por parte dos cursos. Temos recebido muitas mensagens de incentivo e de agradecimentos, muitas delas destacando a grande procura por parte de professores e alunos por artigos da RBMFC. Com esta estratégia alcançamos muitos de nossos potenciais e futuros especialistas, que, normalmente, não tem acesso à informação técnica e científica da especialidade.

Outra boa notícia refere-se à renovação do apoio à SBMFC por parte da Secretaria de Gestão do Trabalho e da Educação em Saúde do Ministério da Saúde e da Organização Panamericana de Saúde, para a edição da RBMFC. Sem este suporte não seria possível constituir a equipe técnica, a impressão e o envio de tiragens cada vez maiores da revista para os sócios da SBMFC, bibliotecas e outros setores estratégicos para a difusão do conhecimento em APS/MFC. A presente edição tem a previsão de tiragem de cerca de 3.000 exemplares. Este é um número impressionante quanto consideramos o tempo de existência da SBMFC e o fato de que as revistas científicas costumam ter uma tiragem média de 150 exemplares. São, portanto, promissoras as perspectivas da RBMFC, contando para isto com o aumento da filiação e da produção científica de seus sócios e da comunidade acadêmica.

* Editor RBMFC. 